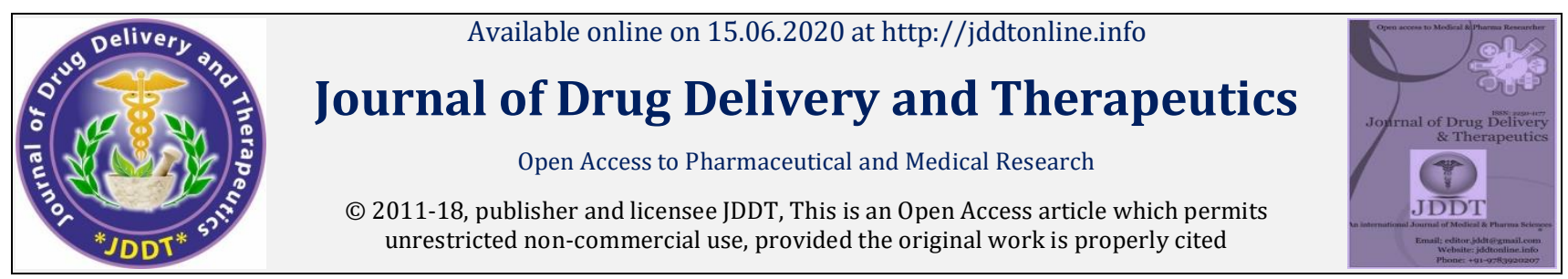

Open $\odot$ Access

Research Article

\title{
A Study on Self-Medication Practice among Nursing Pharmacy and B. Arch Students in a Private Institution
}

\author{
Arshiya A ${ }^{1 *}$, Akhil K Shaji ${ }^{2}$, Tobin Sunny ${ }^{3}$, Ritty Sara Cherian ${ }^{4}$, B A Vishwanath ${ }^{5}$ \\ 1,2,3 Pharm D intern, Department of Pharmacy Practice, ABIPER, Bengaluru, Karnataka, India \\ ${ }^{4}$ Assistant professor, Department of Pharmacy Practice, ABIPER, Bengaluru, Karnataka, India \\ ${ }^{5}$ Chairman of Aditya group of Institution, Bengaluru, Karnataka, India
}

\begin{abstract}
Background: The consumption of drugs without consulting healthcare professional regardless of side effects and duration of therapy is kno wn as self-medication. Objectives: This study was conducted to analyse the practice of SM among the students and to survey pharmacists regarding the practice of drug counselling while dispensing. Methods: 6 months Study was carried out by collecting the data with the help of questionnaire and thereby collecting their answers. The data was analysed statistically in terms of actual numbers and percentage. Results: According to our study the prevalence of SM is higher among juniors than seniors. Previous experience, economy, quick reli ef were most prevailing reasons for SM. Mostly to Fever and headache, acidity, cough, cold and arthritis .Most frequently used medications were analgesics, antipyretics, and antacids, and all they get information is from media, parents and friends most probably. Our study also revealed that in nearby pharmacies most of them were certified pharmacists(96\%),mostly dispensed drugs were without prescription and people do not ask for counselling of the medicine due to lack of time and interest. Conclusion: Our study concluded that the prevalence of SM was seen in higher levels among the students and is the primary reason for irrational use of medicines. Hence proper information has to be given to the students about the negative effects of the drugs and to take proper advice and assistance by a health care professional before taking medication.
\end{abstract}

Keywords: Self-medication, irrational use, prevalence, pharmacist, drugs.

Article Info: Received 24 March 2020; Review Completed 20 May 2020; Accepted 27 May 2020; Available online 15 June 2020

Cite this article as:

Arshiya A, Shaji AK, Sunny T, Cherian RS, Vishwanath BA, A Study on Self-Medication Practice among Nursing Pharmacy and B. Arch Students in a Private Institution, Journal of Drug Delivery and Therapeutics. 2020; 10(3-s):82-85 http://dx.doi.org/10.22270/jddt.v10i3-s.4145

*Address for Correspondence:

Arshiya A, Pharm D Intern, Department of Pharmacy Practice, ABIPER, Bengaluru, Karnataka, India

\section{INTRODUCTION}

Inapt medicinal use is a major problem for ensuring effectual and safe medications. Self-medication is a behavioural response of human being in which an individual uses drugs to treat self-diagnosed minor symptoms or disorders having the potential to do good as well as harm as it involves use of drugs. ${ }^{1}$ It has become worldwide using drugs without proper knowledge just for the sake of quick relief. Self medication can be dangerous and can cause waste of resources, pharmaceutical reactions and possible increase of antimicrobial resistance. ${ }^{2}$ Due to continuous expansion of self-medication in the community, rational use of drugs is affected and reduced. Which is more commonly seen in students of health care profession? The pharmacist role has evolved over time, from being a role of supplier of medicines to being a provider of health care and health services. Pharmacist's responsibilities include ensuring that a patient's drug therapy is appropriately, effectively managed and includes patient counselling. The most common reasons for self medication include prior experience of the illness, inadequate information about the illness, financial or economic problems for visiting a doctor and easy access to medications, especially in the developing countries. ${ }^{3,4}$

Responsible self-medication can be used to prevent and treat symptoms and ailments that do not need medical consultation or oversight. For those populations living in rural or remote areas where access to medical services may be difficult, patients are able to control their own conditions to a greater extent. Only if the condition fails to respond, persists, or becomes more severe than the patient needs to seek professional medical care. However, there are several critical issues that must be explored before promoting the potential benefits of self-medication. Any self-medication product should be safe for use. This implies the availability of appropriate consumer information and avoidance of any delay in diagnosis and treatment of diseases not suitable for 
self-medication. Furthermore, self-medication drugs are known to interact with many prescription-only drugs, alcohol and foods.

\section{MATERIALS AND METHODS}

After obtaining Institutional Ethical Clearance Certificate for the protocol of present study, a cross-sectional, descriptive study was carried out.

Study Design: A cross-sectional, descriptive, prospective, questionnaire-based study was conducted for a period of 6 months from October 2018-March 2019 for assessing the practice of self-medication among Nursing, Pharmacy, and B. Arch students.

Study Site: The study was conducted at Aditya Bangalore Institute of Pharmacy Education And Research and nearby community pharmacies.

Source of Data: A cross sectional descriptive prospective study was conducted with the help of questionnaire in a population of 360 samples.

Study Setting and Collection of Data: A well framed questionnaire was used for the study which consisted of three sections prior to administering questionnaires, students were told about the purpose of data collection, and they were informed that their participation would be voluntary. . After obtaining informed consent for participation the questionnaires were given to them and thereby collecting their answers The medicine obtained through prescription letter and incomplete and ambiguous answers were excluded from the study. ${ }^{4}$ Other side pharmacist in the nearby pharmacies were served questionnaires to measure the practice of patient counselling during dispensing of drugs.

\section{Study Criteria}

\section{Inclusion criteria:}

- All the students of nursing, pharmacy and B.arch in Aditya Institution.

- $\quad$ Students who are willing to participate in the study.

\section{Exclusion criteria:}

- Students who obtained medicine by using prescription letter.

Statistical Analysis: Data was entered in MS Excel 2007 and analysed. Statistics of the study was expressed in terms of actual numbers and percentage was used for data analysis.

\section{RESULTS}

According to the study total number of sample was found to be 400 from which 360 responded to the questionnaire. The section 1 results showed that Among 360 students 51, 141, 168 were from B. Arch , Nursing and Pharmacy respectively (Table 1) of which 174 were males and 186 were females (Table 2). And also number of male students at the age 20 is highest i.e, 42 students and the students of the age 26 comes least i.e only 2 . The number of female students at the age 19 is highest i.e 45 students and the number of females students at the age of 30 is least i.e only 2 students. (Table 3 ).

Fig 1 shows that according to the study the most important reasons for self-medication given by the subjects were previous experience (64.4\%), economical (52.3\%), quick relief $(40 \%)$, urgency $(38.4 \%)$, time saving or lack of time (30\%) respectively

Fig 2 shows that the percentage of students getting information on self-medication from parents (71.5\%), media (52.4\%), chemist (45\%), friends (35.2\%), other prescription (29\%) respectively.

Fig 3 shows that the highest rate of self medication was for treating fever and headache (85\%), acidity (54\%), cold (46\%), arthritis (38\%), cough $(28.3 \%)$, nausea and vomiting $(12.9 \%)$, diarrhoea $(16.6 \%)$ respectively.

It was analysed that the most frequent drugs used for self medications were: analgesics(82.8\%), antipyretics(79.4\%), antacids(75\%), antihistamines(52.3\%), antibiotics(43\%), multivitamins(29.8\%) respectively(Fig4).

According to our study only 113 students said yes when asked about checking the expiry date of the medicine before taking while 247 students said no for the same.

And they were also told like $86.4 \%$ of students were benefitted from self medication and 13.59\%are not benefitted (Table6).

When pharmacist in the nearby pharmacies were served questionnaires to measure the practice of patient counselling during dispensing of drugs. It was showed that most of them were certified pharmacists(96\%),and mostly dispensed drugs were without prescription and people do not ask for counselling of the medicine due to lack of time and interest.

Table 1: Department wise distribution of students

\begin{tabular}{|l|l|l|}
\hline SL NO & Department & $\begin{array}{l}\text { Number of } \\
\text { students }\end{array}$ \\
\hline 1 & Nursing & 141 \\
\hline 2 & Pharmacy & 168 \\
\hline 3 & B.arch & 51 \\
\hline
\end{tabular}

Table 2: Gender wise distribution of students

\begin{tabular}{|c|c|c|}
\hline \multicolumn{3}{|c|}{ Distribution of Gender } \\
\hline Gender & Number & Percentage \\
\hline Males & 174 & 48.33 \\
\hline Females & 186 & 51.66 \\
\hline
\end{tabular}


Table 3: Age wise distribution of students

\begin{tabular}{|c|c|c|c|}
\hline SL.NO. & Age Group & Number of Male Students & Number of Female Students \\
\hline 1 & 17 & 4 & 5 \\
\hline 2 & 18 & 24 & 29 \\
\hline 3 & 19 & 30 & 45 \\
\hline 4 & 20 & 42 & 31 \\
\hline 5 & 21 & 23 & 26 \\
\hline 6 & 22 & 17 & 29 \\
\hline 7 & 23 & 15 & 5 \\
\hline 8 & 24 & 8 & 3 \\
\hline 9 & 25 & 5 & 3 \\
\hline 10 & 26 & 2 & 3 \\
\hline 11 & 27 & 3 & 4 \\
\hline 12 & 28 & 0 & 3 \\
\hline 13 & 29 & 4 & 0 \\
\hline 14 & 30 & 0 & 2 \\
\hline
\end{tabular}

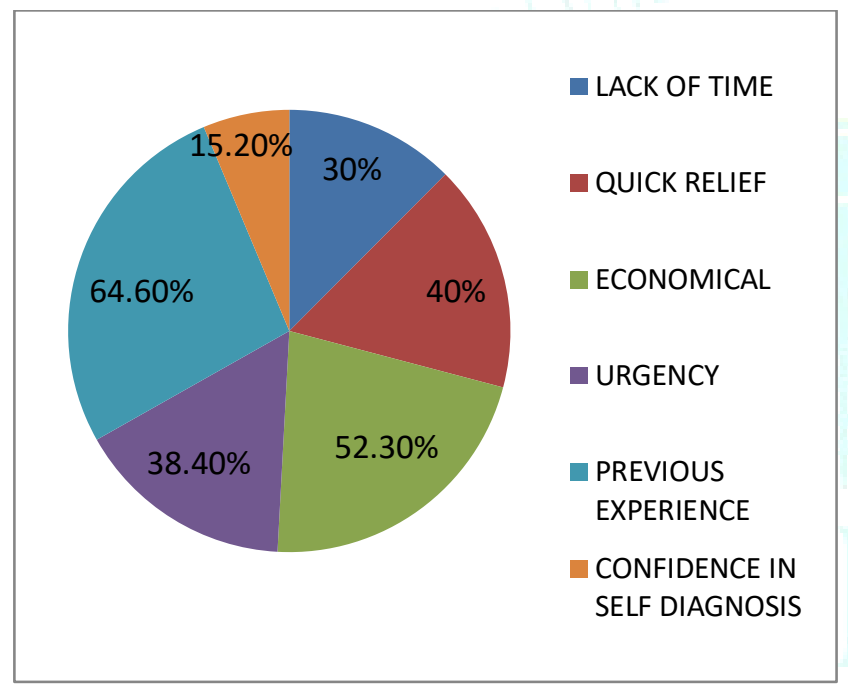

Figure 1: Reasons for Self Medication.

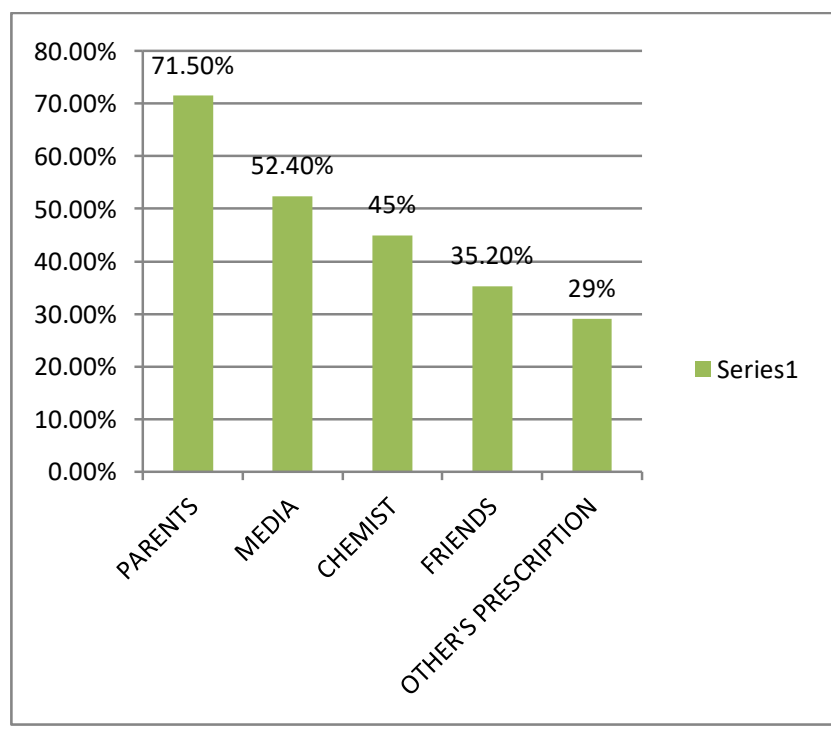

Figure 2: Source of Drug Information.

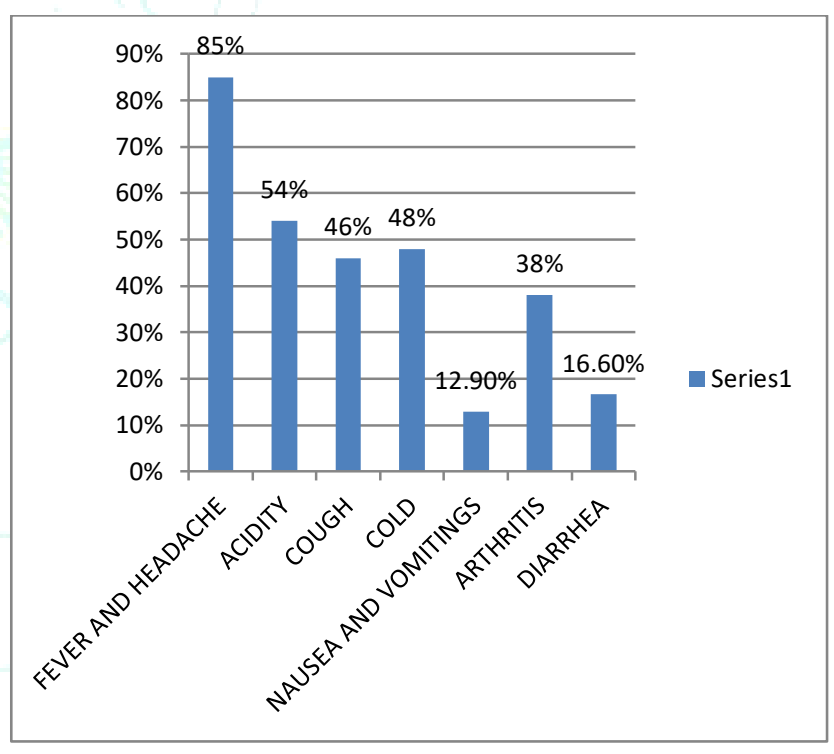

Figure 3: Indications for Self Medication.

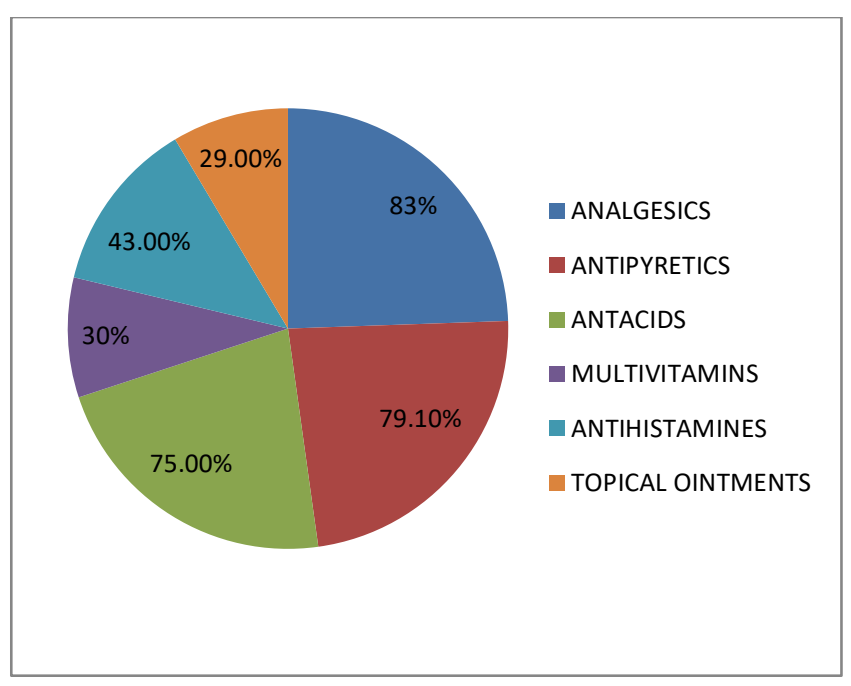

Figure 4: Drugs Used for Self Medication. 


\section{DISCUSSION}

As many studies showed that practice of self medication is prevalent both in literate and illiterate population our study also showed that the practice is in higher level among the students in an institution. In our study among 400 students 360 students responded to the questionnaire. Instead of visiting health care professional people are likely to self medicate them. In developing countries like India, most conditions are treated by self medication due to easy availability of non-prescription drugs. It is a prominent constraint in ensuring the safe and effective use of medicines. It is becoming a routine practice among populations due to incomplete knowledge especially among students.

In our present study among 360 students 151, 141, 168, students were from B. Arch, Nursing and Pharmacy respectively (Table 1) of which $174(48.33)$ were males and 186(51.66) were females (Table 2). In our study the practice of SM had no much difference among males and females which was in regard in some studies that they showed higher $\mathrm{SM}$ in females while some in males. We believe SM is a problem that is not associated with gender and is observed in every person, whether man or a woman. ${ }^{4}$

Results of this study showed that the rate of practice of SM is highest in junior students and least in seniors. Which is consistent with results of other studies (Robert V Lalengtluanga et al., 2016;). This may be due to incomplete knowledge and easy availability of non-prescription drugs which made it a practice of SM.

According to our study most common reason reported were previous experience, economy quick relief and lack of time (fig1) which is also seen in other studies (Arti.A et al., 2015; Robert V Lalengtluanga et al., 2016; Arman Latifi., 2017) as the result of this study showed $64.6 \%$ for previous experience which is high as compared to Arti.A et al., 2015 (12.3\%) and Arman Latifi., 2017(40\%). This showed that in our study students had underestimated and made their diseases simple and also were benefited by their previous SM for the same. In other hand some studies showed high consultation fee and busy schedule (Robert V Lalengtluanga et al.,2016;) as main reason for self medication.

Our study revealed that most of the students are highly aware of SM by getting information from media, family and friends which was also reported similarly in other studies (Robert V Lalengtluanga et al., 2016).

In (fig3) it is shown that fever and headache, acidity, cough and cold were most cases conductive to self medication. These findings are in consistent with other studies (Arti.A et al., 2015; Ali rezaabdi., 2018; Arman Latifi., 2001; Robert V Lalengtluanga et al., 2016), in the most mentioned studies headache and fever is the most common cause of SM as they are the most primary symptoms of many common diseases and the patients have to take medicine to get rid off. Also in our present study most drugs used were analgesics, antipyretics, antacids (fig4) which are needed to treat mostly seen symptoms among population. This statistics is consistent with other studies for analgesics and antipyretics whereas antacids is not much used but these days it has become a worldwide problem and people reason for SM.

\section{CONCLUSION}

Self medication is one of the primary reasons for irrational use of medicines. From our present survey we conclude that maximum number of students in a private institution were practicing self medication and were seen continuing the same. It also revealed that the practice of self medication is more seen in juniors than in seniors due to partial knowledge about the medicines. This practice of taking medications without knowing the side effects, ADRs and expiry dates may take the graph of occurrence of medication errors and interactions to the peak, pharmacist would help in minimising this by providing proper counselling for the medications dispensed but according to the study most of the people donot ask for counselling due to lack of time and interest. Hence conducting education about the negative effects of the drugs for the students is essential. For this we distributed leaflets that may help students to know the benefits and risks of self medication and step back from indulging into such practices.

\section{ACKNOWLEDGEMENT}

We would like to thank Ethical committee for granting us permission for conducting the study and also to the students and staff of Aditya Bangalore Institution of Pharmacy Education and Research for their valuable cooperation and helping us to complete our study.

Conflict of interest: There are no conflicts of interest.

\section{REFERENCES}

1. Arti A, Kar K, Guptha M. A study of self medication practices among medical students of a private institute. Indian journal of pharmaceutical sciences/72(22)/ page number 178 to 182/march 2015.

2. Ali R, Azam F, Fateme, D, Ali RK. A study of self medication practice among health sciences students in keranshahIran BMC Pharmacotoxicology 19:36 July 2018.

3. Latifi A, Ramezankhani A, Zahed Rezai, Hosseib Ashtarian, Behnam Salmani , Mohammad-Reza Yousef, Mehdi Khezeli. a study on prevalence and associated factors of self-medications among the college students in Tehran ,Journal of applied pharmaceutical science Vol.7,pp.128-132, july, 2017

4. A survey study to measure the practice of patient counselling and other community pharmacy services in jordan,133-139 JPHS 2019

5. Lalengtluanga RV, Dimble d, Cherian RS, Ram Kumar K, Kumar P, Vishwanath BA,"A study on self medication practice among nursing, pharmacy, and management students in aprivate institution. Vol 6 issue 09. 22 August 2016,

6. Michael P. et al - 'Medication Adherence' journal of American Heart Association PISSN: 0009-7322

7. Shankar PR, Partha P, Shenoy N, 'Self medication and nonmedical prescription practices in Pokhara valley, Western Nepal/ 3:17/1471-2296/3/17/17 Sept 2002.

8. Kayalvizhi S, Senapathi R, Evaluation of perception, attitude \&practice ofself medication among business students in 3 selected cities in south India.' International journal of enterprise \& innovation management studies/Vol: 1.

9. International Pharmaceutical Federation Statement of principle. Self-careincluding self-medication. 1 September 1996

10. Allen B.E. \& Suveges L.G. Standards of practice. Nonprescription drugs. A report of the National Pharmacy Regulatory Authorities. October 1995 